\title{
Covid-19, patents and access to healthcare: a French perspective
}

\author{
Matthieu DHENNE \\ $\mathrm{PhD}$ (Panthéon-Assas University) \\ Attorney-at-Law (Paris bar) \\ Affiliated researcher (Max-Planck Institute for Competition and Innovation)
}

\begin{abstract}
While the coronavirus 19 (Covid-19) pandemic is forcing a large part of the world's population into quarantine, research into treatment and testing is intensifying. At the same time, patents have rarely been so much in the forefront: how can we ensure that access to care will not be hindered by patents? Should we opt for an ex-officio license, relax the conditions of this license, or even expropriate the patentees? A bill tabled on April 7, 2020 in the French "Assemblée Nationale" could (finally) make it possible to start this discussion in France.
\end{abstract}

§1. From the Wuhan market to the pandemic. - All began at a market in Wuhan - a small town of just 11 million people in China's Hubei province - where a variety of exotic animals, including pangolin, are traded. Although pangolin is illegal to trade, its flesh (for its taste) and scales (for Chinese medicine) are highly prized in China. However, pangolin also appears to have been the natural reservoir (or intermediate host) of a new type of coronavirus: SARS-CoV-2, the origin of the coronavirus 2019 disease (known as "Covid-19") ${ }^{1}$.

SARS-CoV-2, sequenced for the first time on January $11^{\text {th }}$ in China, is, as its acronym indicates, an SARS-type virus of the coronavirus family ${ }^{2}$. Many coronaviruses regularly infect humans, usually causing simple colds and/or sore throats. Coronaviruses normally have a specific host (mammals, birds or reptiles). However, they can sometimes change host as a result of a mutation. The SARS coronaviruses that have appeared since the beginning of the second millennium stem from this type of mutation: SARS-CoV-1 in 2003, MERS-CoV in 2012, SARS-Cov-2 in 2020. The latter thus constitutes an SARS - severe acute respiratory syndrome - virus infecting the lungs and generating inflammation, which may prove fatal for the patient if it becomes severe.

Antivirals, when given early, will have the potential to lower the viral load so that they will inhibit infection with the virus and reduce the chances of the infected individual developing a deleterious inflammatory reaction. Antivirals are effective at an early stage, but once the

\footnotetext{
1 Lam, T.T., Shum, M.H., Zhu, H. et al. Identifying SARS-CoV-2 related coronaviruses in Malayan pangolins. Nature (2020). https://doi.org/10.1038/s41586-020-2169-0

2 National Center for Biotechnology Information, US Library of Medecine.

https://www.ncbi.nlm.nih.gov/genbank/sars-cov-2-seqs/
} 
inflammation has set in, they will no longer be effective, so a different molecule should be considered. Four main treatments have so far been considered, notably in the Discovery clinical trial conducted by INSERM as part of the Reacting consortium: remdesivir (a molecule initially intended for the Ebola virus and then for MERS-CoV); lopinavir in combination with ritonavir (a combination of molecules used against HIV); lopinavir in combination with ritonavir and interferon beta to reduce the inflammatory process (a combination of molecules used against HIV) and hydroxycholoroquine (a cousin of chloroquine used against malaria, but with less risk of toxicity and adverse effects than the latter $)^{3}$. But all these molecules are only antiviral and do not treat, a priori, the inflammation of the lungs observed in severe cases of Covid19. They are therefore unlikely to work for the latter, especially since the viral load in severe cases often appears to be only residual or even nil. A recent clinical trial has concluded that the combination ritonavir-lopinavir is ineffective in treating severe Covid-194. Other trials involving immunosuppressants (pirfenidone and fingolimod, used for lung fibrosis and multiple sclerosis, respectively) or monoclonal antibodies (such as tocilizumab and sarilumab used for rheumatoid arthritis) ${ }^{5}$ seem more promising for severe cases. This is particularly the case for tocilizumab ${ }^{6}$, for which Roche is preparing a phase III clinical trial with the FDA (i.e., the U.S. Food and Drug Administration, which authorizes marketing in the United States) to test it against Covid-197. Tocilizumab and sarilumab are monoclonal antibodies that act by inhibiting the interleukin- 6 receptor, which is involved in the mechanism of inflammation.

§2. The role of patents in the health crisis. - What role do patents play in the current health crisis? It is clear that all the treatments being considered are based on known substances. In terms of patent law, this means that some of them remain covered by titles, on the one hand, and that there are or will be applications relating to the future treatment of Covid-19, on the other hand. With regard to the first hypothesis, the keyword "SARS-CoV" and its more than 3,000 hits on Google Patents are enough to convince us of the plethora of patents targeting coronaviruses of the SARS-Cov-1 and MERS-CoV types. With regard to the second hypothesis, the applicants will be able to claim essentially new therapeutic indications and/or new combinations targeting SARSCoV-2, which will be highly likely, in view of the number of titles in force, to be dependent on earlier titles in the SARS category. In concrete terms, in the immediate future, the manufacture of the miracle drug(s) will depend on the authorisation of patentees and, in the future, the drug(s) will certainly give rise to the granting of patents, then supplementary protection certificates as well as orphan designations. In addition, diagnostic tests or masks may also be protected ${ }^{8}$.

The controversy over remdesivir - an antiviral that appears to be effective at least in the early stages of infection - is symptomatic of this issue, which poses a challenge to patentees and may well be a touchstone for the future in terms of patent law. The company Gilead has developed a molecule known as "remdesivir" to combat Ebola and MERS-CoV. In September 2016, Gilead filed an international application ("PCT"), based on two U.S. priority applications dated 2015,

\footnotetext{
3 INSERM, press release, 22 March 2020, Launch of a European clinical trial against Covid-19.

https://presse.inserm.fr/lancement-dun-essai-clinique-europeen-contre-le-covid-19/38737/

4 B. E. Young, S. W. Xiang, S. Kalimuddin, et al., Epidemiologic Features and Clinical Course of Patients Infected With SARS-CoV-2 in Singapore, JAMA. 2020;323(15):1488-1494.

https://doi.org/10.1001/jama.2020.3204

5 S. Korsia-Meffre, Ongoing therapeutic trials against COVID-19.

https ://www.vidal.fr/actualites/24555/les_essais_therapeutiques_en_cours_contre_la_covid_19/

$6 \mathrm{X}$. Xu et al., Effective Treatment of Severe COVID-19 Patients with Tocilizumab.

https://sfar.org/download/effective-treatment-of-severe-covid-19-patients-with-tocilizumab/

7 N. Viudez, Roche will test its ROACTERMA.

https : //www.industriepharma.fr/covid-19-roche-va-tester-son-roactemra, 109501

8 M. Dhenne, Coronvirus : une guerre des brevets freine-t-elle les dépistages?

https://www. lesechos.fr/idees-debats/cercle/opinion-coronavirus-une-guerre-des-brevets-

freine-t-elle-les-depistages-1188794
} 
for a remdesivir application for MERS-CoV in which it designated more than 100 countries $^{9}$. National applications were filed on this basis in China and Hong Kong, and on April 9, 2019, USPTO granted Gilead US Patent 10,251,904 for "Methods for the Treatment of Arenaviridae and Coronaviridae Virus Infections". Remdesivir, however, remains in an experimental stage: it is in clinical trials for various treatments and has not received regulatory approval as a drug to treat disease by any regulatory agency in any country, including the United States. However, on January 21, the Wuhan Institute of Virology indicated on its website that it had filed a patent application involving the drug. The move came as a surprise, particularly because Gilead was never approached with a view to granting a possible license to the Chinese institute. But the controversy was born. Its paroxysm undoubtedly resides in the open letter of March 30, 2020 addressed by more than a hundred NGOs and a dozen personalities to the CEO of Gilead so that his company would give free access to the remdesivir during the current crisis ${ }^{10}$. On 25 March 2020, Gilead already announced that it was withdrawing the orphan designation it had obtained from the Food and Drug Administration for Covid-19 on $23 \mathrm{March}^{11}$. The withdrawal may signal that it will not exercise its patent right on remodeling either. In any case, AbbVie, which holds the patents on the lopinavir-ritonavir combination ("Kaletra"), announced on 20 March that it would not exercise its rights anywhere in the world, following Israel's decision to issue Ex officio licenses for the same combination ${ }^{12}$.

§3. The role of ex-officio licenses in the health crisis. - The patent law system is based on a balance between the temporary exclusivity granted to the patentee, intended to reward his research effort, and the freedom of trade, to which this exclusivity is an exception. The fundamental aim of this infringement of free competition is to encourage research in the field of technology in order to promote innovation and thus generate growth. However, this balance is subject to safeguards, including: mechanisms intended to prevent the existence of the property right from being unjustified, and therefore harmful because the conditions for patentability are not met, or unjustifiable because its future exercise would necessarily involve an infringement of public policy (opposition action during the examination of the application and then action for annulment of the patent after grant); mechanisms intended to prevent the exercise of the property right from being a source of unjustified blockages (Ex officio licenses).

Although this seems to be a school hypothesis, on reading the case law ${ }^{13}$, one can imagine that exceptions to patentability arising from the protection of public policy could be used to reject applications for inventions whose exploitation could block access to health care (Art. 27(2) TRIPS, Art. 53 EPC and Art. L. 611-17 CPI). This approach therefore seems both uncertain and ineffective, since from this point of view only future applications or those awaiting publication would be concerned and not patents which are already enforceable.

The implementation of the Ex officio license mechanism seems more realistic. A patent license

\footnotetext{
9 Request WO 2017/049060. Note that a similar application also targets hydroxycholoroquine (application WO 2015/157223) to which the team from the Wuhan Institute of Virology associates remdesivir: Wang, M., Cao, R., Zhang, L. et al. Remdesivir and chloroquine effectively inhibit the recently emerged novel coronavirus (2019-nCoV) in vitro. Cell Res 30, 269-271 (2020). https://doi.org/10.1038/s41422-020-0282-0

${ }^{10}$ Open letter to Gilead concerning ensuring access to remdesivir.

https://msfaccess.org/open-letter-civil-society-urges-gilead-take-immediate-action-ensureaccess-potential-covid-19

${ }^{11}$ Gilead Sciences Statement on Request to Rescind Remdesivir Orphan Drug Designation:

https://www.gilead.com/news-and-press/company-statements/gilead-sciences-statement-onrequest-to-rescind-remdesivir-orphan-drug-designation

12 E. 't Hoen, Covid-19 and the comeback of Ex officio licensing.

https://medicineslawandpolicy.org/2020/03/covid-19-and-the-come-back-of-compulsory-

licensing/

${ }^{13}$ M. Dhenne, Technique et droit des brevets, LexisNexis, Bibliothèque droit de l'entreprise, t. 89, Paris, 2016, nos. 495 et seq., p. 290 et seq.
} 
may be defined as a contract of lease by which the patent owner grants to a third party the right to exploit an invention, which constitutes all or part of the subject matter of his title, in return for the payment of a royalty. The patentee is therefore, in principle, as the owner of the property right, free to conclude this contract with whomever he wishes. As an exception, in certain cases specified by law, he may nevertheless be obliged to grant such an authorization for use. In such cases, "Ex officio" licenses are referred to, which require the patentee to have a licensee whom it has not chosen.

§4. Ex officio licensing worldwide. - Article 5 of the Paris Convention of 1883 already provided that contracting countries could take legislative measures, but only to prevent abuses resulting from the exercise of the patent right. Now, the TRIPS Agreement provides, independently of any abuse, conditions under which Ex officio licenses may be granted by members (TRIPS, art. 31). This provision assigns precise boundaries with the exception of: prior negotiation with the right holder; the duration and scope of the license must be limited according to need; the license must be non-exclusive and non-assignable (except with goodwill); granted primarily for the supply of the market of the authorizing member; adequate remuneration; remuneration which must be subject to judicial review or review by a higher independent authority. Finally, Article 31(1) provides for specific conditions in the case where the license relates to a dependent patent: the invention must involve significant technical progress and be of considerable economic interest; the owner of the first patent shall be entitled to a cross-license on reasonable terms to use the invention claimed in the second; and the use authorized in relation to the first patent shall be non-assignable unless the second patent is also assigned.

At the same time, the 2001 Doha Declaration on TRIPS and Public Health affirms the willingness of WTO members to allow more flexibility in the establishment of such a mechanism ${ }^{14}$. Paragraph 6 of that declaration states: "We recognize that WTO Members with insufficient or no manufacturing capacities in the pharmaceutical sector could face difficulties in making effective use of Ex officio licensing under the TRIPS Agreement. We instruct the Council for TRIPS to find an expeditious solution to this problem and to report to the General Council before the end of 2002". In a decision of 30 August 2003, on the implementation of paragraph 6 of the Doha Declaration, WTO members removed a significant barrier to imports of affordable medicines by removing the limitation in the Agreement that made Ex officio licensing conditional on supply primarily for the local market ${ }^{15}$. The decision states that if the importing country cannot ensure access to necessary medicines at affordable prices, such medicines could be produced under Ex officio license by drug manufacturers in third countries and imported into poorer countries unable to manufacture the medicines themselves. Two years later, on 6 December 2005, WTO Members agreed to incorporate the 2003 waiver decision into the Agreement on a permanent basis through the conclusion of a protocol ${ }^{16}$. The entry into force of this amendment on 23 January 2017 was to ensure flexibility to protect public health. It now appears in the Treaty in Article 31(a), added to the Annex thereto. The system introduced essentially resides in two parallel initiatives: an eligible country applies for and obtains a Ex officio license to import, market or distribute the products in question, provided that a need exists, i.e. that a patent is in force on its territory; a laboratory applies for and obtains a Ex officio license to manufacture and export medicinal products. This

\footnotetext{
${ }^{14}$ WTO, Declaration on the TRIPS Agreement and Public Health, 14 November 2001, WT/MIN(01)/DEC/2.

${ }^{15}$ WTO, Implementation of Paragraph 6 of the Doha Declaration on the TRIPS Agreement and Public Health, 30 August 2003, $\mathrm{WT} / \mathrm{GC} / \mathrm{M} / 82$.

${ }^{16}$ WTO, Protocol amending the TRIPS Agreement, W/L/641.
} 
new system has only been used once so far ${ }^{17}$, certainly because of its complexity ${ }^{18}$, although its introduction will have demonstrated the speed and flexibility that the WTO is capable of showing in reforming industrial property at international level ${ }^{19}$.

Indeed, until now, ex-officio licensing in the interest of public health has generally been seen as a favour for developing and least developed countries. India ${ }^{20}$, Brazil $^{21}$ and South Africa ${ }^{22}$ have so far led the most significant campaigns for a more flexible mechanism. The current pandemic should extend the use of this mechanism much more widely, as the examples we already have proven. On 17 March 2020, the Chilean Parliament unanimously adopted a resolution stating that the global Covid-19 epidemic justified the use of Ex officio licensing to facilitate access to vaccines, drugs, diagnostics, devices, supplies and other technologies useful for the surveillance, prevention, detection, diagnosis and treatment of persons infected with the coronavirus in Chile ${ }^{23}$. On 19 March, Israel (which has also granted a number of Ex officio licenses in the past) also announced that such licenses would be granted for the lopinavir-ritonavir combination, before the patentee relinquished its rights on $20 \mathrm{March}^{24}$. On March 20, Ecuador adopted a resolution similar to that of Chile ${ }^{25}$. On March 25, 2020, the Canadian Parliament passed Bill C-13, an Act respecting certain measures in response to Covid-19, which, among other things, introduced a Ex officio license during the Covid-19public health emergency ${ }^{26}$.

§5. Ex officio licensing in Europe. - Regulation (EC) No 816/2006 of May 17, 2006, on Ex officio licensing for the manufacture of pharmaceutical products for export to countries with public health problems implements in the European Union the decision adopted on 30 August 2003 by the WTO following the Doha Declaration ${ }^{27}$. This text aims to establish a single rule on Ex officio licensing for the manufacture and export of medicinal products for Member States. The French legislator amended the provisions of the Intellectual Property Code in accordance with this regulation on the occasion of Act No. 2007-1544 of 29 October 2007 on the fight against counterfeiting (CPI, art. L. 613-17-1 and L. 613-17-2).

However, without German case law, there would be little to say about the practice of Ex officio licenses in Europe. Section 24(1) of the Patentgesetz (German Patent Law) provides that Ex officio

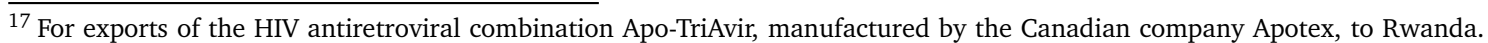
V. P. Ramanujam and Y. Goyal, One view of Ex officio licensing: comparative perspectives from India and Canada: Marquette Intellectual Property Law Review, 2014, p. 394; G. Tsai, Canada's access to medicines regime: lessons for Ex officio licensing schemes under the WTO Doha Declaration: Virginia Journal of International Law, 2009, p. 1076.

${ }^{18}$ B. Anderson, Better access to medicines: why countries are getting "tripped" up and not ratifying article 31-bis : Case Western Reserve Journal of Law, Technology \& the Internet, 2010, p. 173; C. M. Correa, Will the Amendment to the TRIPS Agreement Enhance Access to Medicines?, South Centre, Policy Brief 57, January 2019.

${ }^{19}$ J. Azéma and J.-Ch. Galloux, Droit de la propriété industrielle, Dalloz, Précis Dalloz, 8 ${ }^{\text {th }}$ edition, 2017, no. 694, spec. p. 472.

${ }^{20}$ S. K. Rathod, Ex officio licences on pharmaceutical patents in India: A short article: Journal of Generics Medecines 2017, vol. 13, p. 108.

${ }^{21}$ A. Attaran and P. Champ, Patent Rights and Local Working Under the WTO Trips Agreement: An Analysis of the U.S.-Brazil Patent Dispute, Yale Journal of International Law 2002, vol. 27, p. 365.

22 D. Nash, South Africa's Medicines and Related Substances Control Act of 1997: Berkeley Technology Law Journal 2000, vol. 15, p. 485.

${ }^{23}$ Resolution for the granting of non-voluntary licenses referred to in article $51^{\circ} \mathrm{n}^{\mathrm{o}} 2$ of industrial property law $\mathrm{n}^{\mathrm{o}} 19.030$ to facilitate access and availability of medicines and technologies for the prevention, treatment and cure of coronavirus covid-19. https://www.keionline.org/chilean-covid-resolution

${ }^{24} \mathrm{E}$. 't Hoen, prec.

${ }^{25}$ Resolution to require the National Government to establish Ex officio licenses and other measures to guarantee free and affordable access to pharmaceutical products and medical technologies in the Declaration of Sanitary Emergency due to the Coronavirus pandemic (COVID-19) and other variations, as well as biosafety protocols and instruments for health personnel, postgraduates and students of the Public Health System.

https://www .keionline.org/ecuador-CL-coronavirus-resolution

${ }^{26}$ COVID-19 Emergency response Act.

https ://www . parl.ca/LegisInfo/BillDetails . aspx?Language=EillId=10710867

${ }^{27}$ EP and EC Council, Reg. 816/2006, 17 May 2006: OJEU, 9 June 2006, No. L 157, p. 1. For comments V. J.-Ch. Galloux, RTD com. 2007, p. 52 and J. Schmidt-Szalewski, RTD eur. 2007, p. 347.
} 
licenses may be granted if : $1^{\circ}$ an applicant for a license has, within a reasonable period of time, unsuccessfully attempted to obtain the permission of the patent owner to use the invention on reasonable commercial terms, and if, $2^{\circ}$ the public interest requires the grant of a Ex officio license. This second condition of public interest is at the origin of several important decisions. In the Polyferon judgment of 5 December 1995, such a license was rejected by the Bundesgerichtshof (German Federal Supreme Court), which held that the supply of important medicines to the population could be in the public interest, but that in the present case it had not been proved that Polyferon was an essential medicine. This was, in fact, a strict understanding of the public interest that is difficult to satisfy in practice ${ }^{28}$. In the Raltegravir decision of July 11, 2017, the same Supreme Court granted a Ex officio patent licence, holding that a "public interest" existed if it was proven that the active compound in question had certain therapeutic effects that other commercially available active compounds did not provide, or that by using that active compound the negative side effects (that other active compounds induce) could be avoided ${ }^{29}$. In this regard, it is not relevant whether the user group to which these considerations apply is small, since the difficulties of this small group are significant.

Nevertheless, in order to avoid any possible hiatus in view of the ongoing health crisis, on 27 March 2020 a special law amending the Infektionsschutzgesetz (Infection Control Act) was passed. It is now foreseen that, in the context of the SARS-Cov-2 epidemic, the Federal Minister of Health will be able to invoke Section 13 of the Patentgesetz, which has never been invoked in the past, according to which patents will have no effect if the Federal Government orders that the invention be used in the public interest ${ }^{30}$. We are therefore no longer dealing here with an Ex officio license, but with expropriation, which will have to be compensated by the German State in accordance with Article 14(3) of the Grundgesetz (German Constitution).

§6. Ex officio licensing in France: legislative inaccuracies. - Article 2 of Law No. 2020- 290 of 23 March 2020 introduces a new Article L. 3131-15 into the Public Health Code which provides that "in territorial districts where a state of health emergency is declared, the Prime Minister may, by regulatory decree issued on the basis of a report by the Minister responsible for health, for the sole purpose of guaranteeing public health: [...] $9^{\circ}$ Whenever necessary, take any measure to make available to patients appropriate medicines for the eradication of the health disaster". This provision could perhaps lead to the extreme to which the German legislator has already reached, although the expropriation measure adopted across the Rhine complies with the general provision of Article 8(2) of the TRIPS Agreement, it is nevertheless contrary to the special Ex officio licensing procedure provided for in Article 31 of the Treaty, which should apply here.

A bill No. 2814 of 7 April 2020 was also tabled in the National Assembly by the group La France Insoumise. Following the observation of the fragility of the French health system revealed by the health crisis, its explanatory memorandum calls into question what it calls the "private management of medicines", which would obey a logic of profit to the detriment of the general interest, public research, as well as "a misuse of intellectual property tools" and the research tax credit. Article 1st of the proposal therefore suggests amending Articles L. 613-16 and L. 613-17 of the Intellectual Property Code (CPI), as well as Article L. 5121-10-1 of the Public Health Code, in order to relax the conditions for obtaining a patent office license for a medicinal product and to guarantee faster production of medicinal products when justified by the general interest. Article 2 proposes the creation of a public medicines center, a public scientific and technical establishment with extended responsibilities, which would be responsible in particular for managing operating

\footnotetext{
${ }^{28} \mathrm{Ph}$. Maume, Ex officio Licensing in Germany, in Ex officio Licensing: Practical Experiences and Ways Forward (MPI Studies on Intellectual Property and Competition Law, Vol. 22), under dir. R. Hilty and K.-C. Liu, Springer, 2015, p. 95.

29 BGH 11 July 2017, X ZB 2/17: GRUR 2017, 1017, "Raltegravir".

${ }^{30}$ Act for the Prevention and Control of Infectious Diseases in Humans - Infection Protection Act (IfSG), 27 mars 2020: BGBl. I, p. $587,589$.
} 
licenses, relocating the manufacture of medicines, controlling their price and setting up conditions imposed on the private sector receiving aid for medical research.

If the proposal of April 7, 2020 seems excessive, in particular because of the ignorance of patent law that it reveals, the fact remains that the Ex officio license system would deserve legislative and regulatory clarification in order to be fully effective. Its non-use in France until now is probably the result of several reasons: no pandemic had justified it; the mechanism is complex, so that in the end no one is really in a position to determine how to put it into practice in practice; it certainly remains somewhat demonized, because of the limitation placed on the patentee's right. In any event, since it is an exception, this statutory obligation to grant a license must be interpreted strictly.

De lege lata, two types of Ex officio licenses are distinguished by the Intellectual Property Code. On the one hand, those granted by the judge, who can oblige the patentee to grant licenses when a patent is not exploited (CPI, art. L. 613-11 and L. 613-12) or when the exploitation of a patent is dependent on a prior title (CPI, art. L. 613-15). On the other hand, Ex officio licenses which have the particularity of only coming into being at the end of an administrative procedure that must be initiated by the administration itself in order to satisfy the general interest. At the end of this procedure, candidates for the license may apply to the administration with a view to obtaining a license. The law lists four grounds that may justify an Ex officio license, among which is the Ex officio license in the interest of public health (CPI, art. L. 613-16 CPI and L. 613-17). However, this system has never been used. Probably because no pandemic had so far justified it, but also, on the one hand, because the mechanism is complex, so that in the end no one is really in a position to determine how to put it into practice in practice, and, on the other hand, because it certainly remains somewhat demonized because of the limitation placed on the patentee's right. In any event, since it is an exception, this statutory obligation to grant a license must be interpreted strictly. The texts lay down the conditions for this.

Background conditions first. The exploitation of the patent must be such that it does not meet the needs of the population. Thus, the Ex officio license regime is applicable in case of quantitative or qualitative insufficiency or abnormally high prices, or anti-competitive practices, and more generally in case of exploitation contrary to the interest of public health. It should be noted that insufficient exploitation is particularly difficult to qualify. Except, it seems, when it is a question of fighting an epidemic or dealing with a plague. All the more so since the question arises as to whether only the needs of public health should be taken into account or whether the patentee's ability to make a profit from the research he has had to carry out should also be taken into account. On this point, section 41(2) of the English Act of 1949 was more explicit in stating that medicines should be made available to the public "at the lowest price consistent with the benefits which patentees must equitably obtain from the patents".

This seems reasonable in the interests of funding research. Finally, it is also unclear what an abnormally high price is, or when it is supposed to be considered normally high. In France, however, the price of medicines is not set unilaterally by the company marketing the medicine, but by the Economic Committee for Health Products, usually after negotiations with the company. Moreover, a medicine is often the subject of several patents. In such cases, an Ex officio license will be required for each of the patents in the family in question. A single license for one patent in a family would be unnecessary. Finally, it should be noted that section L. 613-16 CPI, which applies only to patents, does not extend to patent applications. However, not only does the recognition of the patent right result from the filing of the application, but, in addition, many applications will undoubtedly concern the treatment of Covid-19.

The texts then set out procedural requirements. The initiative for the procedure lies with the Minister responsible for public health, who requests the Minister responsible for industrial property to submit the patent to the Ex officio license system by order. The procedure may be initiated only in the absence of an amicable agreement with the owner of the patent, except where the 
purpose of the license is to remedy a practice declared to be anti-competitive or in cases of urgency (CPI, Art. L. 613-16). The order is issued on the basis of a reasoned opinion from a commission whose composition and operation are regulated by Articles R. 613-10 et seq. of the Intellectual Property Code.

To our knowledge, the Ex officio license for public health needs has not been the subject of litigation before the French courts. Only a judgment of 25 January 1991 is worth noting ${ }^{31}$. In that case the Conseil d'État invalid a formal notice issued by the Minister for Health to Roussel Uclaf to resume the operation of a pharmaceutical specialty, on the ground that there was no provision empowering the Minister to issue such a formal notice, the only way of applying the Ex officio license system. This decision is, moreover, proof, if it were necessary, of the prevailing ignorance about the Ex officio license.

If these conditions are met, the license will take effect on the date of its notification to the parties (CPI, art. L. 613-17), it will be non-exclusive (CPI, art. L. 613-13), personal, i.e. it may not be assigned or transferred (except with the business, the enterprise or the part of the enterprise to which they are attached, (CPI, art. L. 613-17), its duration and scope will be fixed by the decree (CPI, art. L. 613-17). If several Ex officio licenses were to be granted, it would seem that they should be granted under identical conditions, in accordance with the order implementing the Ex officio license regime. Indeed, as soon as the patent is subject to the Ex officio license regime, this regime should be identical for any person qualified to exploit it. There is nothing to prevent the provision of products necessary for public health from being satisfied by imports.

§7. Ex officio licensing in France: regulatory obstacles. - Ex officio licensing could also be facilitated by addressing some regulatory obstacles. The license will be granted to manufacture and sell a drug covered by one or more patents, without taking into account the need to also obtain a marketing authorization. A Decree No. 2020-447 of April 18, 2020, which was published in the French Official Journal on April 19, 2020, already authorizes the National Agency for the Safety of Medicines and Health Products (ANSM) to import medicines whose importation has been authorized under Article R. 5121-108 of the Public Health Code and which appear on a list maintained by the ANSM without carrying out the usual controls. This first measure is to be welcomed. Other regulatory obstacles will nevertheless have to be taken into consideration. A license may be requested to manufacture and sell a medicine covered by one or more patents.

But a marketing authorization will still be required. However, it follows from Article 14(11) of Regulation (EC) No $726 / 2004^{32}$ that if the Ex officio license is granted too early, it will fall within the data protection period $(8+2+1$ years) defined by Article 14(11). The licensee will not be able to obtain marketing authorization before the end of this protection (unless he has to redo a whole clinical file). A temporary authorization for use could also prove useful, as it allows early access to a new treatment not yet covered by a marketing authorization for a serious or rare disease (Article L. 5121-12 of the Public Health Code). However, such authorization may be granted only under certain specific conditions, including the absence of an appropriate treatment, which would require that such authorization be obtained by a potential licensee only before the treatments currently being tested are themselves authorized. Not forgetting that it will have to take into account the 10-year market exclusivity if the medicinal product covered by the patent benefits from an orphan designation (Reg. (EC) No 141/2000) ${ }^{33}$, plus 2 years in the case of a pediatric investigation plan (Reg. (EC) No 1901/2006, Art. 37) ${ }^{34}$. Finally, there are no specific

\footnotetext{
${ }^{31}$ EC, 25 January 1991, No. 103 143, National Confederation of Catholic Family Associations.

32 EP and Council Regulation (EC) No 726/2004 of 31 March 2004 laying down Community procedures for the authorisation and supervision of medicinal products for human and veterinary use and establishing a European Medicines Agency: OJEC, 30 April 2004, No L 136, p. 1.

${ }^{33}$ EP and Cons. EC, Reg. No. 141/2000, 16 Dec. 1999, on orphan medicinal products: OJEC, 22 January 2000, No. L 018 , p. 1.

${ }^{34}$ EP and Cons. EC, Regulation No 1901/2006, 12 December 2006 on medicinal products for paediatric use and amending
} 
provisions for supplementary protection certificates. But it could be considered, a fortiori, that these certificates should be subject to the Ex officio license system in accordance with the rules applicable to patents.

§8. Conclusion. - The Covid-19 pandemic will undoubtedly lead to affect patentees' rights. It is to be hoped that this infringement, however legitimate it may be, will nevertheless remain measured and controlled. Let us bear in mind that the patent system is intended to encourage research, which is most often the result of private initiatives, and that any excessive measure could irreparably damage the balance of the system as a whole. Let us rather hope that this pandemic will reveal the usefulness of Ex officio licenses and lead to their un-demonization, so that they may constitute an effective instrument of fair measure within patent law, or even a useful instrument for the economy and research, particularly in France.

Regulation (EEC) No 1768/92, Directives 2001/20/EC and 2001/83/EC and Regulation (EC) No 726/2004: OJEC, 27 December 2006, No L 378/1, p. 1. 